\title{
Yatırımcı Duyarlılığı Endeksi İle BİST 100 Endeksi Arasındaki İlişkinin Araştırılması
}

\author{
Cengiz Çağrı Kabakc1ª, b, Göktuğ Cenk Akkayac
}

\section{Özet}

Davranışsal finans teorisi yatırımcıların piyasalardaki hareketlerinin rasyonel verilerle açıklanamayacak duygusal ve psikolojik kökenlerini araştırmaktadır. Yatırımcların pay fiyatlarına rasyonel olmayan ve söylentiye dayalı olan etkileri yatırımcı duyarlılığı kavramı üzerinden ölçümlenmeye çalışılmaktadır. Çalışmanın amacı Türkiye için yatırımcı duyarlılığını gösteren bir endeks oluşturularak 2008-2019 dönemi için BİST 100 endeksi ile aralarındaki varyansta nedensellik ilişkisinin incelenmesidir. Dokuz adet yatırımcı duyarlılığı temsilcisinden temel bileşenler analizi yöntemi ile elde edilen yatırımcı duyarlılığı endeksi oynaklığından BİST 100 endeksi getiri oynaklığına doğru oynaklık yayılma etkisinin olduğu tespit edilmiştir. Buna karşın, BİST 100 hisse senedi getiri oynaklığından duyarlılık endeks oynaklığına doğru oynaklık yayılma etkisinin olduğuna dair herhangi bir bulguya rastlanılmamıştır.
Anahtar Kelimeler

Davranışsal Finans

Yatırımcı Duyarlılığ

Nedensellik Analizi

Varyansta Nedensellik

Makale Hakkında

Geliş Tarihi: 23.09.2020

Kabul Tarihi: 25.12.2020

Doi: 10.18026/cbayarsos.799208

\section{Investigation of the Relationship between the Investor Sentiment Index and BIST 100 Index}

\begin{abstract}
Behavioral finance theory investigates the emotional and psychological roots of stock market movements and investor demand that cannot be explained by rational factors. The irrational and noisy effects of investors on share prices are tried to be measured through the concept of investor sentiment. The aim of the study is to examine the causality in variance relationship between the BIST 100 index and constructed investor sentiment index for the period 2008-2019. Investor sentiment index obtained by the principal component analysis method from nine investor sentiment proxy. It has been determined that there is a volatility spillover effect from the volatility of the investor sentiment index to the return volatility of the BIST 100 index. On the other hand, there is no evidence that there is a volatility spillover effect from BIST 100 stock return volatility to sensitivity index volatility.
\end{abstract}

Keywords

Behavioral Finance

Investor Sentiment

Causality Analysis

Causality in Variance

About Article

Received: 23.09.2020

Accepted: 25.12.2020

Doi: 10.18026/cbayarsos. 799208 


\section{Giriş}

Psikolojiye dayanan davranışsal finans teorisi, duyguların ve bilişsel hataların bireysel yatırımcıların davranışlarını nasıl etkilediğini anlamaya çalışır. Yatırımcıların belirsizlik şartları altında karar alma davranışları davranışsal yaklaşımla daha iyi anlaşılabilmektedir. Davranışsal finans alanında yapılan araştırmaların çoğu, yatırımcılar da dahil olmak üzere insanların nasıl düşündüklerini, akıl yürütme biçimlerini ve karar verme özelliklerini inceleyen bilişsel psikoloji alanındaki çalışmalardan kaynak bulmaktadır. Geleneksel finansın dayandığı rasyonel yatırımcı kabulü davranışsal finans tarafından reddedilerek sınırlı rasyonellik ve beklenti teorisinin bulguları ile ikame edilmektedir. Rasyonel yatırımcı davranışını baz alan ve finans alanında hakim teori olan etkin piyasalar hipotezine zıt olguları gösteren anomalilerin nedenlerinin neler olduğu davranışsal finansın önemli araştırma konusudur.

Davranışsal bakış açısıyla yatırımcı kararları bir dizi inanç ve tercih tarafından etkilenmektedir. Ortaya çıkan inançlar ve önyargılar yatırımcıların belirli türdeki finansal bilgilere aşırı tepki vermesine ve bazılarına az tepki vermesine neden olarak, onların mantıksız kararlar almasına neden olur ve risk alma davranışlarını etkiler. Hevrestikler, özellikle karmaşık ve belirsiz ortamlarda bir sorunu çözmek için sezgileri kullanarak karar vermeyi kolaylaştırır. Karar alma sürecini basitleştiren hevrestikler aynı zamanda akılcı olmayan bir takım kararların da ortaya çıkmasına neden olmaktadır. Hevrestiklerin ve önyargıların iyi tanınması ve yönetilmesi yatırımcılar için önem taşımaktadır (Bakar ve Yui, 2016, s. 321).

Davranışsal finansın öne çıkan kavramlarından biri de yatırımcı duyarlılığıdır. Yatırımcıların geleneksel modellerle açıklanamayan davranışları nedeniyle piyasadaki menkul kıymet fiyatlarının rasyonel kalıplarla uyuşmayacak şekilde değiştiği hakkında bir çok ampirik kanıt bulunmuştur. Yatırımcı duyarlılığı genel kullanım olarak gelecekteki nakit akımları ve yatırım riskleri ile ilgili eldeki verilerle doğrulanamayan inançlar olarak ifade edilmektedir. Aynı zamanda spekülasyona olan eğilimin göstergesi olarak da kabul edilmektedir. Spekülatif pay senetleri olarak nitelendirilen küçük şirket pay senetleri, genç şirketlerin pay senetleri ve teknoloji şirketleri pay senetlerinde bireysel yatırımcıların duyarlılığı anormal getirilere neden olmaktadır (Baker ve Wurgler, 2006; Baker ve Wurgler, 2007). Yatırımcı duyarlılığının araştırılması mikro açıdan pay senetleri hareketlerine makro açıdan da finansal piyasa hareketlerine verdiği yön ile ilgili olarak yoğunlaşmaktadır.

Yatırımcı duyarlılığı kavramının temelini DeLong, Shleifer, Summers ve Waldmann (1990) tarafından ortaya konulan söylenti yatırımcıları (gürültü tacirleri) modeli oluşturmaktadır. Modele göre yatırımcılar duyarlılık etkisini göstermeyen rasyonel arbitrajcılar ve duyarlılığa meyilli söylenti yatırımcıları olarak ikiye ayrılmaktadır. Piyasalardaki fiyatlandırmaların temel değerlerinden uzaklaşmasının temel nedeni irrasyonel olarak hareket ettiği düşünülen söylenti yatırımcılarının yarattı̆̆ı duyarlılıktaki değişimler ve rasyonel yatırımcıların fiyatları temel değerlerine ulaştırmasını engelleyen arbitraj sınırlılıklarıdır. Lee, Shleifer ve Thaler (1991), daha düşük kurumsal sahipliğe ve daha düşük piyasa kapitalizasyonuna sahip pay senedi getirilerinin, kapalı uçlu yatırım fonlarının iskontolarındaki değişikliklerle pozitif bir şekilde ilişkili olduğunu bulmuşlardır. Kapalı uçlu yatırım fonları öncelikle bireysel yatırımcılar tarafından tercih edildiğinden, bu fonların iskonto oranındaki dalgalanmaların bu yatırımcıların değişen duyarlılığını yansıttığı düşünülmektedir. Barberis, Shleifer ve Vishny (1998) çalışmalarında yatırımcı duyarlılığı için bir model oluşturarak, yatırımcı duyarlılığının etkisinin düşük ya da aşırı tepki sonuçlarına neden olduğunu bulmuşlardır. Tüketici güven 
endeksini yatırımcı duyarlılığı temsilcisi olarak ele alan çalışmalardan Otoo (1999), Brown ve Cliff (2005) pay senedi getirilerinin tüketici güven endeksi getirilerini tek yönlü olarak açıkladığını, Schmeling (2009) ise tüketici güven endeksinin pay senedi getirilerini açıklamada önemli olduğunu ortaya koymuşlardır. Lee vd. (2002) yaptıkları çalışmada doğrudan duyarlılık göstergesi olarak New Rochelle'in Yatırımcı Aklı (Investor Intelligence) Duyarlılık endeksini kullanmışlardır. Duyarlılıktaki değişimlerin piyasa oynaklığı ile ters orantılı olduğunu bunun sonucunda yatırımcılar aşağı yönlü eğilimli (ayı) olduklarında oynaklığının arttığını, yukarı yönlü (boğa) olduklarını oynaklığın azaldığını tespit etmişlerdir. Baumont vd. (2015) yaptıkları çalışmalarda Lee vd. (2002)'ye paralel olarak duyarlılık ile piyasa endeksi getirileri arasında pozitif yönlü güçlü bir ilişkinin olduğunu aynı zamanda endeks getirilerinin oynaklığı ile duyarlılık değişimleri arasında ilişki olduğunu tespit etmişlerdir. Brown ve Cliff (2004) 1965-1998 dönemi içi 406 aylık gözlemler ve 1987-1998 dönemindeki 596 haftalık gözlemler ile gerçekleştirdikleri çalışmada doğrudan ve dolaylı yatırımcı duyarlılığ göstergeleri ile elde ettikleri bileşik yatırımcı duyarlılığı endeksi ile pay senedi getirileri arasındaki ilişkiyi VAR modeli ile incelemişlerdir. Elde edilen yatırımcı duyarlılığı endeksi Kalman filtresi kullanılarak ve seçili serilerin ilk iki temel bileşeni çıkarılarak bulunmuştur. Bireysel yatırımcı duyarlılığınının yanında kurumsal yatırımcı duyarlılığının varlığını da gösteren çalışmada yatırımcı duyarlılığı ile pay getirileri arasında eş hareketlilik (comovement) mevcut olduğu tespit edilmiştir. Yatırımcı duyarlılığı ile piyasa getirileri arasında kısa vadeli ilişkiye rastlanmazken uzun vadeli (2-3 yıl) pozitif korelasyonun varlığ görülmüştür. Çalışmada ayrıca literatürde yer alan dolaylı yatırımcı duyarlılığı göstergeleri ile doğrudan (anket bazlı) yatırımcı duyarlılığı göstergelerinin ilişkili olduğu da bulgulanmıştır. Kumar ve Lee (2006), bireysel yatırımcıların yatırım hareketlerindenki sistematik olmayan davranışları ölçmek için alım ve satım arasındaki dengesizliğe dayalı bir ölçüt (buy-sell imbalance) oluşturmuşlar ve duyarlılığın küçük pay senetleri, değerli pay senetleri ve düşük kurumsal sahipliğe sahip pay senetleri için artan açıklayıcı güce sahip olduğunu bulgulamışlardır. Baker ve Wurgler $(2006,2007)$ yaptıkları çalışmada doğrudan yatırımcı duyarlılığı göstergeleri yerine birden fazla dolaylı göstergenin ortak etkilerinin görülmesinin sağlayacak şekilde temel bileşenler analizi yardımıyla duyarlılık endeksi oluşturmuştur. Oluşturdukları ve literatürde Baker ve Wurgler endeksi(BW) olarak geçen endekste kapalı uçlu yatırım fonları iskontosu, ilk halka arzların yoğunluğu ve ilk halka arzların ilk gün getirisi, temettü primi, pay senetlerinin işlem hacmi, yeni menkul kıymet ihraçlarında pay seneti ihraçlarının ağırlığı değişkenlerini kullanmışlardır. Yatırımcı duyarlılığı etkisinin özellikle yeni kurulan, küçük ve spekülasyona açık pay senetlerinde daha fazla görüldüğünü bulgulamışlardır. Chen, Chong ve Duan(2010) 1998-2006 dönemini kapsayan çalışmalarında açığa satış hacmi, bankalararası faiz oranı (HIBOR), göreli güç endeksi, nakit akış endeksi, yabancı piyasa endeksleri performansları ve piyasa devir oranı değişkenlerini kullanarak Hong Kong borsası için temel bileşenler analizi yardımıyla bir bileşik yatırımcı duyarlılığı endeksi oluşturmuşlardır. Oluşturulan endeks ile piyasa devir oranı göreli güç endeksi, nakit akış endeksi ve yabancı piyasa endeksleri performansının pozitif yönlü ilişkili açığa satış acmi ve bankalararası faiz oranı ile negatif ilişki olduğu bulgulanmıştır. Yang ve Zhou(2015) Çin Şangay Borsası'nda 2005-2014 dönemi için günlük verilerle yaptıkları çalışmada göreli güç endeksi, psikolojik çizgi endeksi, işlem hacmi ve düzeltilmiş piyasa devir oranı göstergelerini kullanarak BW metodolojisine uygun olarak yatırımcı duyarlılığı endeksi oluşturmuşlardır. Yatırımcı duyarlılığı ile artık piyasa getirileri arasında pozitif ve aynı yönlü ilişki bulmuşlardır. Türkiye pay piyasası için yapılan 
çalışmalara bakıldığında, Canbaş ve Kandır (2007) regresyon modeli elde ettikleri sonuçlarda yatırımcı duyarlılığı temsilcileri ile BİST sektör getirileri arasındaki ilişkiyi araştırmışlardır. Yatırımcı duyarlılığının sınai, mali ve hizmetler sektörü getirilerini tahminlemede başarılı olduğu ortaya konmuştur. Uygur ve Taş (2014) yaptıkları çalışmada çeşitli uluslararası borsa endekslerinin getirilerinin koşullu oynaklıkları ile yatırımcı duyarlılığı arasındaki ilişkiyi incelediği çalışmada yatırımcı duyarlılığı endeksi olarak borsalardaki haftalık işlem hacminin bir takım makroekonomik faktörlere olan regresyonunu kullanmışlardır. BİST 100 endeksi için yatırımcı duyarlılığı endeksinin getiri oynaklığı ile pozitif ilişkili olduğunu bulgulamıştırlar. Literatürde doğrudan yatırımcı duyarlılığı temsilcisi olarak tüketici güven endeksleri de sıklıkla kullanılmaktadır. Topuz (2011), Bolaman ve Mandacı (2014), Canöz (2018), Tekin ve Cengiz (2018) BİST 100 endeksinden tüketici güven endeksine tek yönlü nedensellik ilişkisi tespit etmişlerdir. Köse ve Akkaya (2016) yaptıkları çalışmada TC Merkez Bankası Reel Kesim Güven Endeksi'ni yatırımcı duyarlılığı temsilcisi olarak almış ve bu endeksin alt endeksleri ile BIST 100 endeks getirileri arasındaki ilişkiyi incelemişlerdir. Alt endekslerden tüketici güven endeksi ile getiri arasında bir ilişkiye rastlanmamıştır. Keleş ve Arat (2016) çalışmalarında yatırımcı duyarlılığı göstergeleri ile ilgili geniş bir yazın taraması yaparak sıklıkla kullanılan göstergeleri incelemişlerdir. Farklı tüketici güven endekslerinin getiriyi tahmin etmede farklı sonuçlar verebildiğini, bunun aynı zamanda farklı gözlem sayıları ve periyotlar nedeniyle oluşabileceğini belirtmişlerdir. Kaya (2018) temel bileşenler analizi yardımıyla oluşturduğu duyarlılık endeksi ile BİST 100 getirileri arasında pozitif yönlü anlamlı bir ilişki bulmuştur.

\section{Veri Seti ve Yöntem}

Çalışmanın amacı 2008-2019 dönemi için aylık verilerle yatırımcı duyarlılığı endeksindeki oynaklık ile BİST 100 endeksi oynaklığı arasındaki ilişkinin incelenmesidir. Çalışmada kullanılan veriler aylık periyotlarda olup Sermaye Piyasası Kurumu Aylık İstatistik Bültenleri, Borsa İstanbul Resmi İnternet Sitesi, Merkezi Kayıt Kuruluşu, Finnet, Datastream gibi farklı veri sağlayıcılardan elde edilmiştir. Yatırımcı duyarlılığı ile BİST 100 endeksi arasındaki nedensellik ilişkisini araştırmak amacıyla öncelikle yatırımcı duyarlılığını yansıtan farklı tekil göstergeler temel bileşenler analizi yardımıyla bir yatırımcı duyarlılığı endeksine dönüştürülmüştür. Baker ve Wurgler(2006,2007) metodunda bileşik endeks oluşturmak için yatırımcı duyarlılığı bileşenlerini içeren göstergeler temel bileşenler analizi yardımıyla daha az sayıda faktöre indirgenmektedir. Bu faktörlerin toplam varyansı açıklama oranına göre ağırlıklı değerlerine oranlanarak toplanmasıyla makro ekonomik faktörlerden arındırılmamış yatırımcı duyarlılığı endeksi elde edilmiş olmaktadır. Yatırımcı duyarlılığının makroekonomik faktörler tarafından etkilenen kısmı ile birlikte alınmasının bu faktörlerin yatırımcılar için rasyonel karar setini oluşturması nedeniyle bireysel yatırımcı duyarlılığını tam yansitamayabileceği düşünülmektedir. Bu nedenle makro ekonomik faktörlerden arındırılmamış yatırımcı duyarlılığı endeksinin, "İmalat Sanayi Kapasite Kullanım Oranı", "İhracat", "İşsizlik Oranı", "Tüketici Fiyat Endeksi”, "Sanayi Üretim Endeksi” verilerinin mevsim ve takvim etkilerinden arındırılmış biçimde bir önceki aya göre değişimleri cinsinden değerleri üzerine regresyonundan elde edilen hata terimleri yatırımcı duyarlılığı endeksi olarak kullanılmıştır. Finter vd. (2012) metodolojisine uygun olarak doğrudan ve dolaylı yatırımcı duyarlılılığı temsilcileri birlikte kullanılmıştır. Dolaylı yatırımcı duyarlılığı göstergeleri olan; İlk Halka Arz İlk Gün Getirileri, İlk Halka Arz Sayıları, Pay Senedi Piyasa Devir Oranı, Menkul Kıymet Yatırım Ortaklığı İskontosu, Yatırım Fonlarının Ortalama Fon 
Akışı, Yeni İhraçlarda Pay Senedi Oranı, Yabancı Yatırımcıların Net Pay Senedi Alımlarının BİST Piyasa Değerine Oranı ve doğrudan yatırımcı duyarlılığı göstergeleri olan Risk İştahı Endeksi (RISE) ve TÜİK Tüketici Güven Endeksi olmak üzere dokuz adet gösterge analize dahil edilmiştir. Yatırımcı duyarlılığı ile BİST 100 arasındaki nedensellik ilişkisi Hafner ve Herwartz (2006) Varyans Nedensellik Testi ile araştırılmıştır.

\section{Bulgular}

İlk olarak, BİST 100 endeksi ile duyarlılık endeksine ilişkin tanımlayıcı istatistikler Tablo 1'de gösterilmektedir.

Tablo 1. BİST 100 Endeksi ve Duyarlılık Endeksine İlişkin Tanımlayıcı İstatistikler

\begin{tabular}{|c|c|c|}
\hline & GBİST 100 & GDUYARLILIK \\
\hline Ortalama & 0.005020 & $-6.97 \mathrm{E}-05$ \\
\hline Medyan & 0.007300 & 0.007322 \\
\hline Maksimum & 0.205785 & 0.473433 \\
\hline Minimum & -0.262928 & -0.734309 \\
\hline Standart Sapma & 0.076673 & 0.199086 \\
\hline Çarpıklık & -0.388280 & -0.604425 \\
\hline Basıklık & 3.863748 & 4.249676 \\
\hline Jarque-Bera & $8.094648^{* * * *}$ & $18.13804^{* * * *}$ \\
\hline$Q(50)$ & 43.667 & 62.241 \\
\hline $\mathrm{Q}^{2}(50)$ & $79.306^{* * *}$ & 15.948 \\
\hline $\mathrm{ARCH}(5)$ & $3.1553^{* * * *}$ & 1.5496 \\
\hline $\mathrm{ARCH}(10)$ & $3.4544^{* *+*}$ & 0.6491 \\
\hline
\end{tabular}

Not: ${ }^{* * * * *},{ }^{*}$ sirasiyla $\% 1, \% 5$ ve $\% 10$ önem seviyelerinde anlamlılıkları göstermektedir. Değişkenlerin başında yer alan G harfi, söz konusu değişkenlerin logaritmik farkı alınarak elde edilmiş getiri serilerini ifade etmektedir.

Tablo 1'de yer alan sonuçlar incelendiğinde, BİST 100 endeksinin sıfıra yakın ve pozitif olduğu, duyarlılık endeksi için örneklem ortalamasının negatif ve sıfırdan oldukça uzak olduğu ifade edilebilir. BİST 100 endeksine ilişkin standart sapma değerinin duyarlılık endeksinden daha büyük olduğu, BİST 100 endeksi serisinde oynaklığın daha yüksek olduğu görülmektedir. Finansal zaman serileri analizinde çarpıklık ve basıklık değerleri, değişkenlerin dağılımı hakkında bilgi vermektedir. Serinin normal dağılıma sahip olması için basıklık değerinin 3'e, çarpıklık değerinin ise 0 'a eşit olması gerekmektedir. Her iki serinin çarpıklık değerlerinin negatif, basıklık değerinin ise 3' den büyük olduğu görülmektedir. Diğer bir ifadeyle, her iki serinin sola çarpık olduğu ve kalın kuyruk özelliği gösterdiği anlamına gelmektedir. Bu durum, her iki seriye ilişkin Şekil 1'de yer alan yoğunluk fonksiyonlarından da görülmektedir. 
Şekil 1'den görüldüğ̈̈ üzere, BİST 100 ve DUYARLILIK endekslerine ilişkin yoğunluk fonksiyonları, söz konusu değişkenlerin sola çarpık ve aşırı sivri olduğu, kalın kuyruklara ve aşırı değerlere sahip oldukları ifade edilebilir. Bu sonuçlar, serilerin normal dağılıma sahip olmadıklarını leptekurtik dağılım gösterdiklerini ortaya koymaktadır.
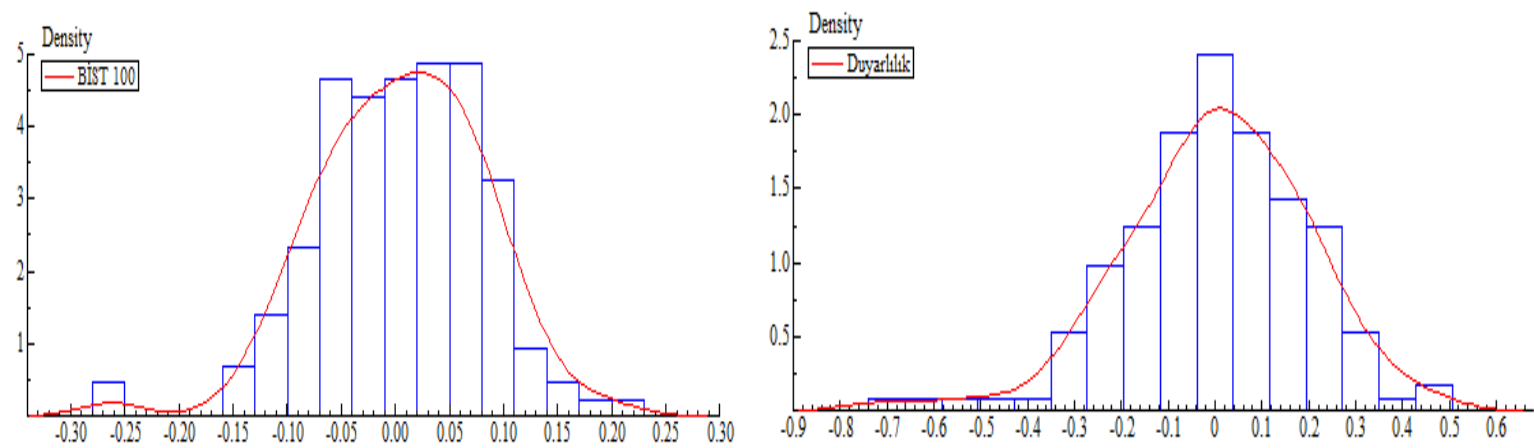

Şekil 1. BİST 100 Endeksine ve Duyarlılık Endeksine İlişkin Yoğunluk Fonksiyonları Şekil 2' de BİST 100 ve DUYARLILIK endekslerine ilişkin 2008:01-2019:12 dönemi için zaman yolu grafikleri yer almaktadir.
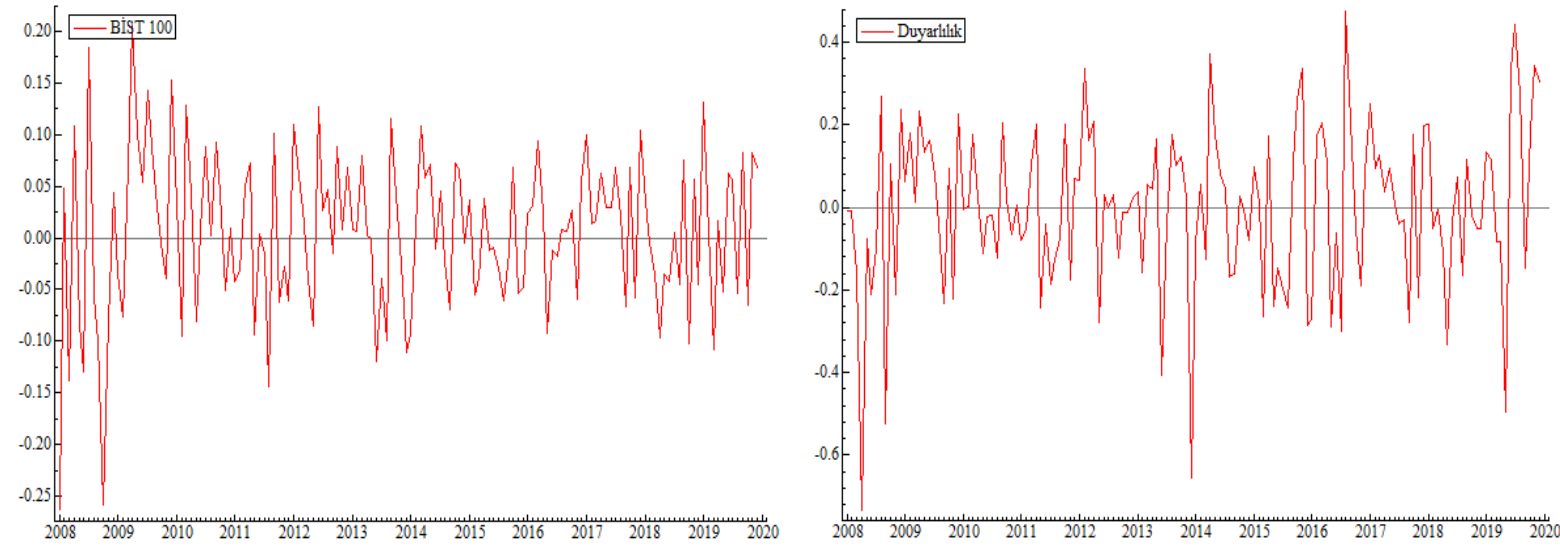

Şekil 2. BİST 100 ve Duyarlılık Endeks Getirilerine İlişkin Zaman Yolu Grafikleri

Şekil 2' de yer alan grafikler incelendiğinde getiri serilerinde meydana gelen küçük değişmeleri küçük değişmeler, büyük değişmeleri ise büyük değişmeler izlediği görülmektedir. Bu durum serilerde oynaklık kümelemesi olduğunu göstermekte ve değişen varyansın varlığına işaret etmektedir. Aynı zamanda, Ljung $\mathrm{Q}^{2}$ istatistiği ile $\mathrm{ARCH}$ istatistiğinin istatistiksel olarak anlamlı olması da bu sonucu desteklemektedir. BIST 100 getiri serisinde ARCH etkisi görülmesinden ötürü modellemeye Genelleştirilmiş Otoregresif Koşullu Değişen Varyans Modelleri (GARCH türü) ile tamamlanmıştır.

GARCH türü modellerin tahmini yapılmadan önce serilerin durağanlıklarının araştırılması gerekmektedir. Veri setinin finansal kriz ve çalkantı dönemlerini içermesi nedeniyle serilerin durağanlıklarının araştırılmasında Clemente, Montanes ve Reyes (1998) tarafından geliştirilen ve iki yapısal kırılmaya izin veren Clemente-Montanse-Reyes birim kök testi uygulanmıştır. Sonuçlar Tablo 2' de yer almaktadır. 
Tablo 2. Clemente-Momtanse-Reyes Birim Kök Test Sonuçları

\begin{tabular}{lllll}
\hline & & du1 & du2 & $\begin{array}{c}\text { Kirılma } \\
\text { Tarihleri }\end{array}$ \\
\hline BİST 100 & İstatistik değeri & 0.12481 & -0.0572 & $2008: 12$ \\
& t istatistiği & 3.863 & -2.261 & $2009: 09$ \\
& Olasılık değeri & 0.000 & 0.026 & \\
DUYARLILIK & İstatistik değeri & 0.327 & 0.1655 & $2013: 10$ \\
& t istatistiği & 3.097 & 2.246 & $2019: 04$ \\
& Olasılık değeri & 0.023 & 0.026 & \\
\hline
\end{tabular}

Tablo 2' de yer alan Clemente-Momtanse-Reyes birim kök test sonuçları incelendiğinde, BİST 100 ve duyarlılık endekslerinin ikisinin de \%5 önem seviyesinde değişkenlerin birim kök içerdiğini söyleyen sıfır hipotezinin reddedildiği görülmektedir. Bu sonuçlar, her iki endeksin de düzey değerlerinde durağan oldukları ifade edilebilir. Değişkenlerin durağanlıklarının araştırılmasının ardından, duyarlılık endeksinin BİST 100 endeksi üzerindeki etkisini ortaya koymak amaciyla ARMAX(0,0,1)-GARCH(1,1) modeli tahminlenmiştir. Tahminlemede, BİST 100 serisi normal dağılıma sahip olmadığından dolayı, Student $t$ dağılımı dikkate alınmıştır. Sonuçlar Tablo 3' de yer almaktadır.

Tablo 3: ARMAX(0,0,1)-GARCH(1,1) Model Tahmin Sonucu

\begin{tabular}{|c|c|c|c|c|}
\hline & Katsayı & Standart Hata & t-değeri & t-prob \\
\hline \multicolumn{5}{|c|}{ Ortalama Denklem } \\
\hline Sabit & 0.007397 & 0.00501 & 1.477 & 0.1421 \\
\hline Duyarlılık & $0.167816^{* * *}$ & 0.031951 & 5.252 & 0.000 \\
\hline \multicolumn{5}{|c|}{ Varyans Denklemi } \\
\hline Sabit & $0.000235^{* * *}$ & $4.7167 \mathrm{e}-005$ & 4.983 & 0.000 \\
\hline ARCH(Alpha1) & $0.094145^{* *}$ & 0.04895 & 1.923 & 0.0565 \\
\hline GARCH(Beta1) & $0.841918^{* * *}$ & 0.040186 & 20.95 & 0.000 \\
\hline Student(DF) & $9.224276^{* * *}$ & 3.6255 & 2.54 & 0.000 \\
\hline Akaike & -2.5708 & & & \\
\hline $\mathrm{Q}(50)$ & 41.5662 & & & \\
\hline $\mathrm{Q}^{2}(50)$ & 26.8392 & & & \\
\hline $\mathrm{ARCH}(1-2)$ & 0.2336 & & & \\
\hline $\mathrm{ARCH}(1-5)$ & 0.50537 & & & \\
\hline
\end{tabular}

Not: ${ }^{* * * * *},{ }^{*}$ sirasıly $\% 1, \% 5$ ve \%10 önem seviyelerinde anlamlılıkları göstermektedir.

Tablo 3'de yer alan sonuçlar incelendiğinde, ortalama denkleminde yer alan Duyarlılık endeksi \%1 önem seviyesinde anlamlı ve pozitiftir. Elde edilen bulgu, duyarlılık endeksinin 
BİST 100 endeks getirisini pozitif olarak etkilediğini göstermektedir. Varyans denkleminde yer alan tüm parametreler de \%5 önem seviyesinde anlamlıdır. Hata terimlerine uygulanan Ljung Box $\mathrm{Q}$ ve $\mathrm{Q}^{2}$ otokorelasyon ve $\mathrm{ARCH}$ testi sonuçları dikkate alındığında, hata terimlerinde otokorelasyon ve farklı varyans problemlerinin ortadan kalktı̆̆1 görülmektedir. Bununla birlikte, Student $\mathrm{t}$ dağılımına ilişkin parametrenin \%5 önem seviyesinde anlamlı olarak elde edilmesi, BİST 100 endeks getirisinin negatif asimetri ve kalın kuyruk özelliğine sahip olduğunu ifade etmektedir. Varyans denkleminde yer alan ARCH parametresi ilk şokun etkisini, ARCH ve GARCH parametrelerin toplamı ise şokun kalıcılığı hakkında bilgi vermektedir. Tahmin sonuçlarına göre, $\mathrm{ARCH}$ ve $\mathrm{GARCH}$ parametrelerin toplamının 0.9369 yakın olduğu görülmektedir. Elde edilen bu sonuç, BIST 100 serisinde oynaklığın kalıcı olduğunu ve gelen bir şokun kalma süresinin ortalama 10 gün olduğu anlamına gelmektedir.

Şekil 3'de ARMAX(0,0,1)-GARCH(1,1) model tahmin sonuçlarından elde edilen artık kareler ve standartlaştırılmış artıklara ilişkin grafikler yer almaktadır.

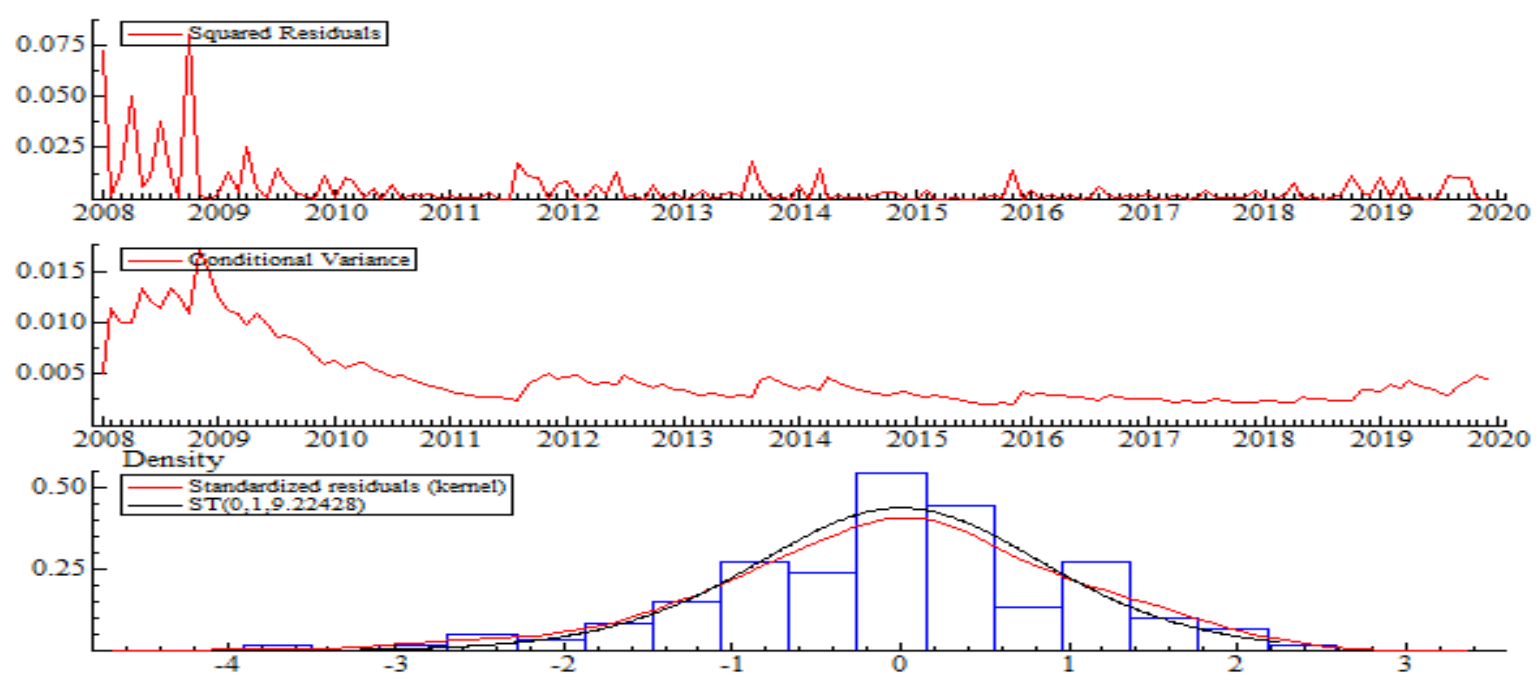

Şekil 3. BİST 100 Endeksine Yönelik ARMAX(0,0,1)-GARCH(1,1) Modeline İlişkin Artık Kareler, Koşullu Varyans ve Standartlaştırılmış Artıklar

Son olarak, BİST 100 endeksi ile duyarlılık endeksi serileri arasında nedensellik ilişkisinin varlığ1 Hafner ve Herwartz (2006) varyans nedensellik testi ile araştırılmıştır. Sonuçlar Tablo 4 'de yer almaktadir.

Tablo 4. BİST 100 ile Duyarlılık Endeksi Arasındaki Hafner ve Herwartz (2006) Varyans Nedensellik Test Sonucu

\begin{tabular}{|c|c|c|}
\hline Varyansta Nedensellik & $\lambda$ LM & p-value \\
\hline Duyarlılık Endeksi Oynaklığı $\longrightarrow$ BİST 100 Oynaklığı & 9.627 & 0.0081 \\
\hline BİST 100 Oynaklığı $\longrightarrow$ Duyarlılık Endeksi Oynaklığı & 1.318 & 0.5175 \\
\hline$* * * \% 1$ düzeyinde istatistiksel açıdan anlamlılığı ifade etmektedir. &
\end{tabular}

$\lambda$ LM istatistiği sonuçları değerlendirildiğinde, \% 1 anlamlılık düzeyinde duyarlılık endeksi oynaklığından BİST 100 hisse senedi getiri oynaklığına doğru tek yönlü nedensellik ilişkisinin olduğu söylenebilir. Diğer bir deyişle, duyarlılık endeksi oynaklığından BİST 100 hisse senedi 
getiri oynaklığına doğru oynaklık yayılma etkisinin olduğu tespit edilmiştir. Buna karşın, BİST 100 hisse senedi getiri oynaklığından duyarlılık endeks oynaklığına doğru oynaklık yayılma etkisinin olduğuna dair herhangi bir bulguya rastlanılmamıştır.

\section{Tartışma ve Sonuç}

Günümüzde finansal piyasaları ve pay senetlerinin hareketlerini anlamak için geleneksel finans teorisinin yetersiz kaldığı ve davranışsal finans ile desteklenmesi gerektiği görülmektedir. Literatüre bakıldığında yatırımcı duyarlılığının etkilerinin yanında yatırımcı duyarlılığ 1 ölçütlerinin de tespiti önemli bir araştırma konusudur. Çalışmada Türkiye için doğrudan (Illk Halka Arz İlk Gün Getirileri, İlk Halka Arz Sayıları, Pay Senedi Piyasa Devir Oranı, Menkul Kıymet Yatırım Ortaklı̆̆ı İskontosu, Yatırım Fonlarının Ortalama Fon Akışı, Yeni İhraçlarda Pay Senedi Oranı, Yabancı Yatırımcıların Net Pay Senedi Alımlarının BİST Piyasa Değerine Oranı) ve dolaylı yatırımcı duyarlılığı temsilcilerinin (Tüketici Güven Endeksi, Risk İştahı Endeksi) modele dahil edildiği kapsamlı bir duyarlılık endeksi oluşturulmuştur.

Ekonomik ve finansal endişe dönemleri yüksek oynaklık ile ilişkilendirilmektedir. Pay fiyatlarının gelecekteki değerleri oynaklık ile genellikle pozitif yönde ilişkili olmaktadır (Kadilli, 2014: 6). Bollerslev, Tauchen ve Zhou (2009)'a göre getirilerdeki yüksek orandaki değişimlerin gelecekteki getirileri pozitif olarak etkilemesinin nedeni yüksek oynaklığın fiyatlara iskonto primini eklemesidir. Aynı zamanda yatırımcı psikolojisi açısından da yüksek oyanklık bazı dönemlerde yatırım firsatı olarak algılanabilmektedir.

Çalışmada elde edilen sonuçlara göre BİST 100 endeksi için yatırımcı duyarlılığı etkisinin söz konusu olduğu anlaşılmaktadır. Yatırımcıların rasyonel nedenlerle ya da makroekonomik verilerin etkisi ile açıklanamayacak davranışlarının meydana getirdiği yatırımcı duyarlılığındaki oynaklığın BİST 100 endeksinin fiyat oynaklığına neden olduğu anlaşılmaktadır. Elde edilen sonuç Lee vd. (2006), Uygur ve Taş (2014) çalışmalarında elde edilen bulgularla uyumludur. Bu açıdan bakıldığında bireysel ve kurumsal yatırımcıların portföylerini oluştururken aynı zamanda yatırımcı duyarlılığını da göz önüne alarak işlem yapmalarının menfaatlerine olacağı söylenebilir.

Yatırımcı duyarlılığı etkisi ile ilgili yapılan çalışmalar anomaliler, finansal krizler ve piyasada temel verilerle açılanamayan fiyat hareketlerini açıklamaya yardımcı olabilir. Korku, risk iştahı ve çeşitli psikolojik faktörle açıklanabilecek beklentilerin neden olduğu yatırımcı duyarlılı̆̆ı finansal piyasalardaki etkinliği tartışmalı hale getirmektedir. Psikolojik önyargilarının tespit edilmesi ve yönetilmesi için ölçülebilir ve gözlemlenebilir veriler haline getirilmesi gerekmektedir. Yatırımcıların piyasa ile ilgili duygusal eğilimlerinin karşılığı olarak yatırımcı duyarlılığının önemle takip edilmesi hem finansal kurumlar hem de yatırımcılar için yol gösterici niteliktedir. Gelecekte yapılacak çalışmalarda yatırımcı duyarlılığı etkisinin farklı analiz yöntemleri ve farklı veri grupları ile de tekrarlanarak ampirik bulgularla desteklenmesi faydalı olacaktır.

\section{Kaynakça}

Bakar, S. \& Yi, A.N.C. (2015), The impact of psychological factors on investors' decision making in Malaysian stock market: a case of Klang valley and Pahang, Procedia Economics and Finance, Vol. 35, 319-328. 
Baker, M., \& Wurgler, J. (2006). Investor sentiment and the cross-section of stock returns. The Journal of Finance, 61(4), 1645-1680.

Baker, M., \& Wurgler, J. (2007). Investor sentiment in the stock market. Journal of Economic Perspectives, 21(2), 129152.

Barberis, N., Shleifer, A., \& Vishny, R. (1998). A model of investor sentiment. Journal of Financial Economics, 49(3), 307-343.

Bolaman, Ö., \& Evrim, P. (2014). Effect of investor sentiment on stock markets. Finansal Araştırmalar ve Çalışmalar Dergisi, 6(11).

Bollerslev, T., Tauchen, G., \& Zhou, H. (2009). Expected stock returns and variance risk premia. The Review of Financial Studies, 22(11), 4463-4492.

Brown, G. W., \& Cliff, M. T. (2004). Investor sentiment and the near-term stock market. Journal of empirical finance, 11(1), 1-27.

Brown, G. W., \& Cliff, M. T. (2005). Investor sentiment and asset valuation. The Journal of Business, 78(2), 405-440.

Canbaş, S., \& Kandır, S. Y. (2007). Yatırımcı duyarlılığının İMKB sektör getirileri üzerindeki etkisi. Dokuz Eylül Üniversitesi İktisadi ve İdari Bilimler Fakültesi Dergisi, 22(2).

Canöz, İ. (2018). Borsa İstanbul 100 endeksi ile tüketici güven endeksleri arasındaki nedensellik ilişkisi: Türkiye örneği. Fiscaoeconomia, 2(1), 136-153.

Chen, H., Chong, T. T. L., \& Duan, X. (2010). A principal-component approach to measuring investor sentiment. Quantitative Finance, 10(4), 339-347.

Clemente, J., Montañés, A., \& Reyes, M. (1998). Testing for a unit root in variables with a double change in the mean. Economics Letters, 59(2), 175-182.

De Long, J. B., Shleifer, A., Summers, L.H., \& Waldmann, R.J. (1990). Noise trader risk in financial markets. Journal of political Economy, 98(4), 703-738.

Finter, P., Niessen-Ruenzi, A., \& Ruenzi, S. (2012). The impact of investor sentiment on the German stock market. Zeitschrift für Betriebswirtschaft, 82(2), 133-163.

Hafner, C. M., \& Herwartz, H. (2006). A Lagrange multiplier test for causality in variance. Economics Letters, 93(1), 137-141.

Kadilli, A. (2014). Return predictability in international financial markets and the role of investor sentiment,

Working Paper in Geneva School of Economics and Management, Unversity of Geneva.

Kaya, E. (2018). Yatırımcı duyarlılığ1 ve hisse senedi getirileri. Finans Politik \& Ekonomik Yorumlar, 55(645), 91-112.

Keleş, E. \& Arat, M. E. (2016). Yatırımcı duyarlılı̆̆1 temsilcileri ve sermaye getirilerinin tahmini. Marmara Üniversitesi Öneri Dergisi, 12(45), 307-326.

Köse, A. K. \& Akkaya, M. (2016). Beklenti ve güven anketlerinin finansal piyasalara etkisi: Bist 100 üzerine bir uygulama. Bankacılar Dergisi, 99, 3-15.

Kumar, A., \& Lee, C. M. (2006). Retail investor sentiment and return comovements. The Journal of Finance, 61(5), 2451-2486.

Lee, C. M., Shleifer, A., \& Thaler, R. H. (1991). Investor sentiment and the closed-end fund puzzle. The journal of finance, 46(1), 75-109.

Lee, Charles MC, Andrei Shleifer, \& Richard H. Thaler. (1991) Investor sentiment and the closed-end fund puzzle. The Journal of Finance 46(1), 75-109.

Lee, W. Y., Jiang, C. X., \& Indro, D. C. (2002). Stock market volatility, excess returns, and the role of investor sentiment. Journal of banking E Finance, 26(12), 2277-2299.

Otoo, M.W., 1999. Consumer sentiment and the stock market. Working Paper, Federal Reserve Board of Governor.

Schmeling, M. (2009). Investor sentiment and stock returns: Some international evidence. Journal of Empirical Finance, 16(3), 394-408.

Tekin, B., \& Cengiz, S. (2018). Pay senedi piyasası ile tüketici güven endeksi arasındaki nedensellik ve eşbütünleşme ilişkileri. Journal of Social And Humanities Sciences Research (JSHSR), 5, 29.

Topuz, Y. V. (2011), Tüketici güveni ve hisse senedi fiyatları arasındaki nedensellik ilişkisi: Türkiye örneği. Ekonomik ve Sosyal Araştırmalar Dergisi, 7(1), 53-65.

Uygur, U., \& Taş, O. (2014). The impacts of investor sentiment on returns and conditional volatility of international stock markets. Quality \& Quantity, 48(3), 1165-1179.

Yang, C., \& Zhou, L. (2015). Investor trading behavior, investor sentiment and asset prices. The North American Journal of Economics and Finance, 34, 42-62. 